\title{
How to use a survey as a marketing tool: a case study of Loughborough University Library
}

\author{
Tracy Marshall and Sharon Reid
}

\begin{abstract}
With increasing competition from external information sources, academic libraries need to undertake strong marketing initiatives to redress the balance.

Evidence-based practice and evaluation of internal services may help to secure the future permanency of the academic library. In light of this, an initiative was undertaken by the Engineering Team at the University Library at Loughborough University to market its services and resources to the Engineering Faculty. A survey was utilised as the marketing tool. It was made available in electronic format and marketed via the Library website, Team blog and targeted emails. Evaluation of the results enabled the Team to further raise its profile by taking various issues directly to the Faculty and actively marketing avenues of communication, training sessions and the Institutional Repository. As a marketing tool the survey approach was largely successful and subject teams may wish to use this approach as a component of their marketing strategy.
\end{abstract}

\section{Introduction}

Marketing is that function of the organization that can keep in constant touch with the organization's consumers, read their needs, develop products that meet these needs, and build a program of communications to express the organization's purpose.

(Kotler and Levy quoted in Duke and Tucker, 2007, 52)

In keeping with a general thrust throughout the professional workplace for evidence-based practice, there is an evolving and recognised drive within the UK academic library sector to evaluate its services. The positive outcomes from a

\section{Tracy Marshall}

Tracy Marshall is Academic Librarian for the Department of Chemical Engineering and the Wolfson School at Loughborough University. She is also a member of the Marketing and Publications Group.

Email: T.M.Marshall@ lboro.ac.uk

\section{Sharon Reid}

Sharon Reid is a Senior Library Assistant in the Engineering Team at the University Library, Loughborough University. She is also a member of the Marketing and Publications Group.

Received June 2008 
profile-raising marketing campaign are a useful means of addressing this need. This article describes a case study carried out at Loughborough University which utilised a survey as a marketing tool to achieve this objective.

It is becoming increasingly accepted by library professionals that academic libraries must actively market their services and resources to users. Not least of the reasons for this change in mindset is the need to justify the very existence of the academic library given the contemporary emphasis on all things 'virtual'. The growing perception among users, particularly new users, is that everything they require to pursue their studies can be obtained by electronic means, particularly the Internet and powerful search engines like Google. Perhaps inevitably, users have come to question the physical relevance of their institution's library, given the more generally held belief that all their information needs can be met by the click of a button from the relative comfort of the bedroom.

For the academic library, competition from other sources has become a real force to be reckoned with. The consequences of this have been brought sharply into focus in recent years by a spate of staff restructuring and even redundancies in a number of university libraries. There has been an almost wholesale wakeup call to the fact that, where they once reigned supreme as the ultimate knowledge and information provider, many academic libraries now have to justify their very existence.

In particular, the role or pertinence of the professional librarian has been called into question. With institutional budgets increasingly stretched, the question has been raised as to whether the traditional librarian is becoming expendable. There has evolved a very real need to justify the relevance of this role to counter any perception that it has become replaceable in the modern academic arena.

There are many other reasons why marketing has become a very real concept for the academic library. Although space limits the ability to expand further, for some institutions such reasons will include budgetary constraints, increasingly complex resources available in an array of formats, competition from other institutions, and, with the advent of student fees, the requirement to be seen to be providing value for money.

Although most academic libraries now involve themselves in active marketing initiatives for the library as a whole, there is little evidence to suggest that individual subject teams have adopted a similar approach. Given that academic librarians in particular need to raise their profile to validate their role, it is important that they receive the support and championing of their subject Faculty staff. With this end in mind, marketing the services of subject library teams has never been more relevant.

In response to this need, the Library Engineering Team at Loughborough University believe that a survey has considerable potential as a marketing tool. Simultaneously, it can raise awareness of services and resources as well as providing evaluated data for profile raising activities. 


\section{Background}

For generations libraries have been seen as "major players in the information industry" (Snoj and Petermanec, 2001, 314). As Kaufman $(2007,8)$ states, the library has been "the jewel in the university's crown, the heart of the university, the campus's treasure". This has meant that until recently academic libraries did not need to consider competitors or market forces, some libraries believing marketing "beneath the profession" (Duke and Tucker, 2007, 52).

The last ten years has seen the creation of a plethora of ways to communicate and access information. Libraries now have competition from publishers, websites and wikis, to name but three, all offering access to information. Many users may feel there is little point visiting the library if they can access all the information they need online, so perhaps it is unsurprising that " $73 \%$ of college students say they use the internet more than the library" (Jones quoted in Duke and Tucker, 2007, 54). When identifying how to market our resources perhaps the idea that "marketing the library means looking at everything the library does for a user" (Boden and Davis, 2006, 1) is a good starting point.

There has also been a vast increase in electronic resources available from libraries, including databases, e-books and e-journals, many with differing interfaces and methods of access. These electronic resources are often very expensive and for the library to obtain value for money they must be fully utilised. Librarians have a vital role to play in ensuring these resources are target-marketed on a consistent basis and in educating and training users to use them effectively. Many students do not understand the difference between website resources located via a popular search engine and using a database to retrieve peer reviewed articles and reports.

Usage statistics and survey results are all useful tools for the librarian to show value for money and "demonstrate the value and impact of those services to institutional managers ever eager to cut costs" (Creaser, 2006, 154). This need to show the impact of our services suggests that raising the profile of the library within the institution has become of key importance.

Along with this increase in the need for librarians' skills there is a similar increase in user expectation and demand, as Kaufman states:

The demands and expectations of an on-demand generation, grown up in the digital age, who demand instant access delivery, and control.

(Kaufman, 2007, 7)

In order that the library meets user expectations and demands, the librarian must market its resources to keep in touch with their users: "If libraries do not keep in touch with users, the users will find other alternatives for their information needs" (Duke and Tucker, 2007, 53). Marketing library resources can be seen as a way of achieving this.

The great changes in the work academic librarians do, along with the changes in information formats, styles of learning and institutional management mean that librarians can no longer afford to be passive in order to maintain their role. As Toft $(2004,42)$ says "'the role of the librarian and co-operation and collaboration 
between academics and librarians, is becoming ever more essential". It is essential that both academics and students realise the work that librarians do, as without this understanding there is a chance that the position of the Academic Librarian will be undermined and finally considered unnecessary. This is well demonstrated in the actions of Bangor University where several subject librarians were made redundant with the reasoning that their contribution was "hard to justify in value for money terms" (Tysome, 2005, 1).

Many academic libraries are now using marketing techniques to justify their status. As Spalding and Wang explain:

Libraries are discovering that by using marketing principles and techniques they can understand better their users needs, justify funding, communicate more effectively with a variety of external audiences and achieve greater efficiency and optimal results in delivering products and services that meet the identified needs of their clients.

(Spalding and Wang, 2006, 494)

Although time consuming, the Library Engineering Team at Loughborough University agreed that a survey "can reveal interesting and important information about user perceptions and priorities" (Bancroft, 1998, 222). Certainly Weingart and Anderson suggest that the main finding from their survey was that University libraries need to work harder to publicize the available electronic resources, how to access them, and what each database has to offer.

(Weingart and Anderson, 2000, 132)

\section{Context of the survey}

In May 2007 the Library Engineering Team at Loughborough decided to undertake a broad-ranging survey of academic staff within the Faculty of Engineering. From the outset, it was viewed as akin to a pioneering exercise in service and resource promotion from which much would be learned about subject team marketing.

Surveys have always been an attractive tool to indicate levels of user satisfaction but have been largely ignored in terms of marketing. For this reason, the Engineering Team decided to adopt a new approach and to utilise the outcomes of its 'Have Your Say' survey to inform the Team's strategic marketing initiative. This was viewed as a proactive and evidence-based means of promoting the Team's services and resources to academic staff within the Faculty. It was also a major part of an initiative to improve its services to the Faculty. As a result, it was felt that the profile of the Team would be raised significantly, in addition to showing its customers that:

- The Team listens to their views, and

- The Team acts on them by providing the focussed services they need.

The survey was viewed as a timely follow-up to a previous survey carried out in 2001 which had successfully informed the strategic direction of engineering collection development. Team members were in agreement that, in view of 
significant changes in both personnel and service provision since 2001, this was an appropriate time at which to initiate a more wide-sweeping, generic survey.

Rapid technological change has seen greater emphasis on online resources, including interactive training materials, and the advent of Web 2.0 initiatives within the Team such as the new blog, Broadcast. To date, the introduction of new services has been on an ad hoc basis based on a perception of what the Faculty would like the Team to provide. It now seemed an appropriate time at which to introduce largely evidence-based strategic planning and marketing.

The 2007 'Have Your Say' survey was to be a measurable means of gauging the level of Faculty understanding, knowledge and appreciation of the Team's services and resources. In addition, there was an urgent need to determine how best the Team should adapt to meet the Faculty's ongoing and changing needs. By marketing the Team's services and resources more effectively and adopting a targeted marketing approach when necessary, it would be possible to distinguish between the needs of different categories of staff within the Faculty.

The Team decided to focus specifically on a number of issues. These included:

- How aware were the Engineering Faculty of the range of services and resources provided by the Library Engineering Team?

- Why were the Engineering Faculty reluctant to add resources to the newly created Institutional Repository and how could this be addressed?

- Which mode of news delivery and general communication between the Engineering Team and Faculty was preferred - blog, email, RSS feed, etc?

- What type of training for Faculty academics would be most useful?

The promotion and marketing of the survey, evaluation of its results and implementation of subsequent actions would all be crucial in determining its success as a marketing tool.

\section{Survey design and distribution}

The decision had been taken that a survey would be an appropriate means of acquiring the data needed to determine team policy and action. Pitching the format, style and tone appropriately was viewed as key to producing volume and quality of feedback. From the start, it was felt that a democratic approach should be adopted with all Team members encouraged to consider the type of questions needed and how these should be formulated and presented. This would have the dual benefit of producing a broad range of interesting ideas and sharing the workload.

With this in mind, an initial brainstorming exercise was undertaken to elicit ideas and suggestions. From these, a draft was produced which adopted a purely openended style of questioning. In spite of its fresh and eye-catching style, it was felt that recipients may be put off by the level of personal thought and input required to respond. Following Team feedback, this draft was subsequently adapted radically to incorporate these views and concerns. 
It was the Team's perception that the final version (Appendix 1) was an example of good practice, as it:

- Varied the style of questioning (open-ended, tick boxes and yes/no options);

- Ensured the right tone - concise and snappy with no intimidating questions and the inclusion of sub-headings designed to engage the recipient. Thus: Have your say! -- Your most wanted -- Help!;

- Avoided professional jargon;

- Took no longer than 5-10 minutes to complete.

Overall, the aim was to engage the recipient by trying to convey the message that completing the survey would be of potential benefit to them and was not a favour to be carried out for the Engineering Team itself. What could the Team do to enhance their individual experience of our services and resources? The survey was then trialled by a couple of University academics and no major revisions were determined to be required.

The 2001 survey had adopted a traditional printed approach with copies being delivered via the internal post. In view of the increasing availability of services and resources electronically, it was decided that the 2007 survey would best be presented as an online version with printed copies only being distributed if feedback proved inadequate. Internal online survey software was utilised for this purpose.

An online survey has to be promoted extensively. It was decided that to maximise uptake a variety of methods would be adopted to reach the target audience, with links to the survey where appropriate. As the survey coincided with the launch of Broadcast, the Engineering Team blog, this was felt to be an appropriate place to advertise the survey. Posts were included on the Library website promoting both the newly established blog and the survey and direct links provided therein. On the blog itself a post, complete with eye-catching cartoon, was also included to direct readers to the survey (Figure 1). 


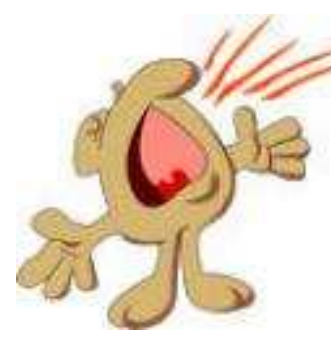

\section{Have your say!}

May 23, 2007

Now's your chance to give the Library Engineering Team a piece of your mind! How? By filling in our short online survey which asks if we can do anything better to help you. We are always working to improve the services we offer the Engineering

Faculty, and need to understand what you want before we can deliver.

So, please take five minutes to fill it in. There is a link from our "Blogroll" on the right hand side of the screen or you can go direct to

http://picture-box.lboro.ac.uk/Public/UCCASS/survey.php?sid=44

Results will be reported in future Blog posts. Thank you!

No Comments $» \mid$ Uncategorized | Permalink

8 Posted by Lizzie Gadd

Figure 1. Engineering blog post advertising 'Have Your Say' Survey

All targeted personnel were also emailed, with two subsequent follow-up messages being sent a fortnight later. Recipients were given approximately four weeks in which to respond.

\section{Results}

\subsection{Response Rate}

The survey received a total of 91 responses. The number of staff in the Engineering Faculty in 2005/6 was 561.35, making the response rate approximately $16 \%$. Respondents were asked how they would classify themselves in terms of staff type. Almost half the respondents were $\mathrm{PhD}$ students. Onequarter were academic staff, and just under one quarter salaried research staff. There are approximately 161 academic staff, 173 contract researchers, and 361 postgraduate researchers currently in the Engineering Faculty. The ratio of respondents is almost exactly representative of the target population.

\subsection{Awareness of services}

The majority of respondents were either aware of, or had used, two of our key services: book ordering and enquiry answering. There was less awareness of our training courses as $40 \%$ of the respondents were unaware that we provided information literacy training. However, only $23 \%$ were unaware that we provided study skills training and almost one-third of respondents had used the service.

Individual induction appointments had been used by 17 of the respondents (18\%). However, 53\% were unaware that we offered individual inductions. Similarly, $50 \%$ were unaware of our online newsletter, Broadcast. 


\subsection{Resources}

\section{Databases}

Respondents were asked to list their "Top three most wanted Library resources". The results produced 60 specific databases or publishers of online collections. Excluding databases we already had (e.g. Web of Science), eight appeared more than once in the list. Access to the full online collection of IEEE/IET material via IEEE Xplore was purchased within weeks of the survey closing. Further Science Direct backfiles were also purchased after the survey.

\section{Journals}

At Loughborough University serial selection takes place within the departments. However, the survey highlighted four titles that would be considered "general" titles (Science and Nature online, the Journal of Learning Science and the Journal of Engineering Education). Subsequently this request has been referred to the Library's Collection Manager.

\subsection{Training needs}

Respondents were asked to complete the sentence, "I could do with some more training in...". This question elicited answers from 20 individuals, with a total of 23 suggestions put forward. These may be divided into the following categories:

\begin{tabular}{|l|l|}
\hline Category & $\begin{array}{l}\text { No. } \\
\text { responses }\end{array}$ \\
\hline Databases / journal article retrieval & 10 \\
\hline Finding information quickly & 3 \\
\hline RefWorks & 1 \\
\hline Interlibrary Loans & 1 \\
\hline Cross-referencing tools & 1 \\
\hline Other / not relevant to Library & 7 \\
\hline
\end{tabular}

Table 1: Responses concerning training needs

The results indicate that additional time spent on database training would be advisable for both academic staff and researchers.

\subsection{Institutional Repository}

The survey results showed that $50 \%$ of respondents were familiar with the Institutional Repository (IR). Nineteen of the 23 responding academics said they had heard of it, $50 \%$ of the research staff had, and just $25 \%$ of PhD students. The second question asked respondents to complete the sentence, "I'd put my research papers in the Institutional Repository if...". Only 23 responses were received and these are listed in Table 14. 


\begin{tabular}{|l|l|}
\hline Theme & No. respondents \\
\hline Lack of time / not a priority & 5 \\
\hline Copyright restrictions & 4 \\
\hline Needs to be easier & 4 \\
\hline Lack of incentive & 2 \\
\hline Don't know how & 2 \\
\hline Already use the IR & 2 \\
\hline Lack of central organisation & 2 \\
\hline Other & 2 \\
\hline
\end{tabular}

Table 2: Responses concerning Institutional Repository deposits

Most respondents answered that they did not have time to submit items to the Institutional Repository. This was disappointing, as library personnel perform all copyright checks and downloading of articles to the IR.

\section{Key Outcomes}

Good communication with the Faculty was viewed as an essential component for effective Team marketing. A major part of the drive was to evaluate how to improve those methods aimed at increasing communication between the Library Engineering Team and the Faculty staff. Library staff found that often members of the Engineering Faculty are unsure of the basics, such as how to order books or who their Academic Librarian is, despite this information being on the Library web pages. The Library Liaison Officer (often a Lecturer) is appointed by the department to provide communication between the department and the Library. However, it has been noted that often information from the Academic Librarian is not communicated around the Faculty staff.

The survey opened up a number of marketing opportunities for the Library Engineering Team. It provided a vehicle to engage in focussed dialogue with academic colleagues in the Engineering Faculty via such activities as meetings with the Library Liaison Officers, utilisation of the Engineering Team blog, targeted emails to staff and students and attendance at departmental meetings. In addition, the survey highlighted the need to undertake a number of tailored training courses for staff and researchers to address those gaps in knowledge and expertise brought to light by the survey. It also spotlighted aspects of the service that needed to be promoted more heavily: electronic resources, the Institutional Repository and research induction interviews.

In the first instance, Academic Librarians informed the Library Liaison Officers of the survey results. These meetings allowed academic staff and researchers to discover exactly what their colleagues wanted from the Library and whether these were achievable.

This was further developed by the informal nature of the aforementioned staff training courses which also encouraged conversation and provided an ideal forum in which to promote the Team's key resources and services, as well as raising the 
profile of Team members and their individual roles. It was also a good opportunity to discuss key issues between academics, researchers and Library staff in a relaxed environment. The opinions of academic staff on Library issues were canvassed as well as training provided in areas they had specifically requested when responding to the survey. The timing of the courses was chosen as the inter-semester period in January, when teaching has finished, exams have started but marking has not begun in earnest. The location was also important: Library staff ensured that a room was booked in the central area of the Engineering Faculty so that all academics could reach it easily.

The content of the course focussed on survey responses, including the request by Faculty staff for more 'instruction on databases'. This was achieved by demonstrating the MetaLib portal and describing the type of information that could be found using MetaLib. This demonstration dealt with the newly purchased IEEE Xplore database which engineering academics had specifically asked for in the survey, highlighting the Team's proactive nature.

The electronic journal demonstrations focussed on the Science and Nature magazines which were purchased after analysing the survey results. These purchases were highlighted on the blog with the headline 'You asked for it' showing that the Team does listen to its users. The Team was also very keen that staff understood how to use the electronic journals. As many seemed unaware of the digitization of academic journals, they may have been 'missing out' on this important source of academic research.

The lack of awareness of research induction interviews was also discussed with Faculty members as many of those attending these courses were still not aware of this service. Although Library staff already sent letters to all new Faculty staff inviting them to visit their Academic Librarian, it was felt that the uptake could still be improved, and the opportunity was taken to market these strongly.

The courses also provided an opportunity to correct misinformation. For example, some respondents appeared unaware of a number of the Engineering resources, requesting databases that were already subscribed to. Instruction sheets and literature highlighting the databases to which the Library subscribes were given to the attendees. Contact details of the Academic Librarians and further information about the Team blog was also included in the literature. It was felt that information regarding communication preferences and service expectations were gained. The opportunity was also taken to put forward the idea that the email details of the Academic Librarians appear in all departmental handbooks to encourage communication. Academic Librarians also requested that they be present at both staff meetings and undergraduate staff student committees to advertise services and heighten their profile. Out of five departments, four now have the Academic Librarian's contact details within their handbook, and three out of five now invite the Academic Librarian to attend staff and student committees.

The results of the survey showed that email was the preferred form of communication ( $75 \%$ of respondents). It was decided that email would continue to be used in a focussed way to highlight targeted services to researchers. Whilst acknowledging this preference, with the advent of the blog the Team have decided 
to modify the use of email. Although it is still used to give information about new resources and courses, a link to the blog is now included to provide further information and encouragement to feed back to library staff.

The Institutional Repository (IR) at Loughborough University has been successful, with over a thousand items deposited at the time of writing. However, there have been a disproportionately low number of items in the IR deposited by the Engineering Faculty. In order to promote the IR effectively, the Library Engineering Team used the survey to try to ascertain why this has been the case. As seen in the results section, many Faculty members felt they did not have the time to deposit items into the IR. It was also found that many Faculty members, primarily researchers and $\mathrm{PhD}$ students, were unaware of the Repository, suggesting that members of research staff producing papers did not realise they could submit them to the Repository. This encouraged the Team to consider how best to target these particular sectors. After contacting academic staff at the 'Research training courses' the team decided on the following actions to promote the IR:

- to contact all departmental administrators to ascertain which students were near PhD completion, thereby enabling the Team to target its marketing at these students;

- to follow up the course with individual emails to all researchers in the Faculty;

- to trace all new publications from staff in the Faculty and ask for copies for the IR;

- to use the blog to advertise the IR on a regular basis.

It is too early to be able to evaluate whether these actions have had an effect. Certainly the number of articles in the IR has increased, but not dramatically. The Team feels the promotion of the IR will be an ongoing process that will need to be reviewed regularly.

As outlined, a variety of methods are now used to improve the Team's communication with the departments. From a marketing perspective, it is hoped that this will have an ongoing positive influence on raising the profile of the Engineering Team.

\section{Conclusion}

The 2007 'Have Your Say' survey proved to be a useful marketing tool for the Library Engineering Team. It achieved its overall aim which was to evaluate its service and to subsequently promote and further market it to Faculty staff. Although recognised that there would be a continued requirement to review the situation on a regular basis, it was no longer necessary to rely to such an extent on perceived Faculty expectations of the Team. The survey garnered sufficient evidence-based data for the outcomes to inform strategic planning and a series of marketing activities for the forthcoming academic year and possibly beyond. It also enabled the Team to target services more effectively and to determine priorities. 
Although the survey was initiated to generate feedback to help shape the Team's marketing strategy, it is worth noting that a survey is a very useful means in itself for promoting Team services and resources. Put simply, it was a marketing exercise which, from the outset, gave the profile of the Team a welcome lift. Based on the evidence acquired, the Team has been able to take a number of issues directly to the Faculty and to market its services and resources in a more productive manner. This has included the ability to address any gaps in knowledge and a lack of awareness of some resources, largely through profileraising Faculty staff training sessions. A number of steps for further promoting the IR are now in place and it is hoped that this will have a knock-on effect on deposits from the Engineering Faculty.

Broadcast, the Engineering Team's blog has been mentioned a number of times throughout this article. As it was launched simultaneously with the survey it would be inaccurate to describe its subsequent active promotion by the Team as a direct outcome of the exercise. However, by successfully utilising the blog to both advertise and link to the survey its potential as a major marketing tool has became evident. It has provided the Team with a new and interesting way of communicating with the Faculty and has continued to flourish. In time, when the survey is repeated, it will be possible to fully evaluate its effectiveness.

To a significant extent, the survey has opened up a general dialogue between the Engineering Team and the Faculty. There now exists a greater degree of mutual understanding and recognition of the importance of the respective roles of librarian and academic. The Faculty has been made more aware that Library staff are keen to work cooperatively with them, not least by taking a participatory role on departmental committees. It is hoped that Faculty staff will have a greater appreciation of the benefit to themselves, especially in terms of specialist subject knowledge, of enhanced communication between Faculty and Library subject team. Given the immense changes and challenges currently faced by academic libraries, it is essential that forward-thinking and profile-raising activities are undertaken as the norm to ensure their future relevance in the eyes of individuals, faculties and institutions as a whole.

\section{Benefits and lessons learned from the survey approach to marketing}

Making people aware of its existence and ensuring accessibility is obviously key to the success of an online survey. In this case, the actual process of promoting the survey was helped by the simultaneous launch of the Team blog. This provided another helpful medium from which to link to the survey as well as securing a useful means for marketing the blog itself. The profiles of other forms of Team communication, such as wikis and online newsletters, could also be raised in this way. A link from a news advertisement on the Library website to those resources where the survey can be accessed is an excellent promotional tool.

An added benefit of the exercise lay in its value as a learning experience. Not only was the democratic approach adopted a useful way of involving all Team members in a shared activity, but also, much was learnt about putting a survey together and how best to promote it. Although a considerable amount of time and effort by a number of people went into getting the 'Have Your Say' survey right, 
mistakes were still made and for those planning a similar activity, the following recommendations and suggestions may be helpful:

- A healthy response rate is not guaranteed. Ensure that all means of marketing the survey are explored and if necessary send reminder emails to recipients;

- Avoid professional jargon - allow people from outside of the profession to pass opinion as they will spot unfamiliar terms immediately. With hindsight, the inclusion of the term 'information literacy' in this survey was inappropriate;

- Ensure all questions are well constructed to avoid invalid or misleading statistical outcomes - question 1 (Appendix 1) included tick boxes for both 'aware of' and 'used'. On analysis, it was realised that whereas some respondents who had 'used' a service had also ticked the 'aware of' box, others had deemed it necessary to tick the 'used' box only. Therefore, the subsequent graphical representation of the results was somewhat misleading. If using online software, consider whether the results will be graphically meaningful and accurate;

- Getting the wording right is key to the success of individual questions for example, if you provide a list of suggestions, the respondents may simply select one of these options and not consider a more broad-ranging response (question 2, Appendix 1). Also, try to determine whether the wording could be misconstrued - the use of the phrase 'Most-wanted' in this question led some respondents to state their preferred or favourite resources, some of which the Library already held! With hindsight, it may have been helpful to add "which resources would you like the Library to obtain for you?" There is a fine line between ensuring the questions are succinct and to the point but also clear in meaning;

- Be aware that some questions may elicit few responses. In some cases, it may be inappropriate, or at least unwise, to base strategic development on these sparse outcomes. Further investigation may be necessary;

- A survey may not provide all the answers - the format needs to be short and snappy to ensure good feedback, but this may mean insufficient coverage of key issues. In other words, you may not be able to determine everything via a single survey. In the Team's effort to ensure the survey was of an optimum length, the opportunity to raise the profile of the Team's four Academic Librarians by including a question relating to their names and subject responsibilities was lost. This is an issue to be addressed in a future survey. 


\section{References}

Bancroft, A. (1998) A forward-looking library use survey: WSU Libraries in the $21^{\text {st }}$ century. The Journal of Academic Librarianship, 24 (3) 216-223.

Boden, D. and Davis, L. (2006) Developing a marketing mindset. Library and Information Update, 5 (5) 38-39.

Creaser, C. (2006) One size does not fit all: user surveys in academic libraries. Performance Measurement and Metrics, 7 (3), 153-162. URL:

http://www.emeraldinsight.com/Insight/viewPDF.jsp?Filename=html/Output/Publ ished/EmeraldFullTextArticle/Pdf/2790070303.pdf [accessed 02.06.].

Duke, L.M., and Tucker, T. (2007) How to develop a marketing plan for an academic library. Technical Services Quarterly, 25 (1), 51-68.

Högg, R. et al., (2006) Overview of business models for Web 2.0 communities. In: Proceedings of GeNeMe 2006, $28^{\text {th }}$ September 2006, Dresden. [s.1.] : [n.p.].

23-37 [online]. URL: http://www.alexandria.unisg.ch/Publikationen/31411 [accessed 02.06.08].

Jones, S. (2002) The internet goes to College: how students are living in the future with today's technology. In: Duke, L.M., and Tucker, T., op cit.

Kaufman, P. (2007) It's not your parents' library anymore: challenges and opportunities in the new webs of complexity. Journal of Library Administration, $46(1), 5-26$.

Kotler, P. and Levy, S. (1969) Broadening the concept of marketing. In: Duke, L.M., and Tucker, T. op cit.

Snoj, B. and Petermanec, Z. (2001) Let users judge the quality of faculty library services. New Library World, 102 (1168), 314-324.

Spalding, H.H. and Wang, J. (2006) The challenges and opportunities of marketing academic libraries in the USA: experiences of US academic libraries with global application. Library Management, 27 (6/7), 494-504.

Toft, Z. (2004) What can librarians do for us? An academic's perspective. Library and Information Update, 3 (1), 42-43.

Tysome, T. (2005) Librarians under threat. The Times Higher Education Supplement, February 11, No. 1678; 8 [online].URL:

http://www.lexisnexis.com/uk/nexis/search/newssubmitForm.do [accessed 28.04.08].

Weingart, S. and Anderson, J.A. (2000) When questions are answers: using a survey to achieve faculty awareness of the Library's electronic resources. College and Research Libraries, 61(2), 127-134. 


\section{Acknowledgement}

The authors wish to acknowledge the work of their colleagues in the Library Engineering Team in undertaking the initial survey of the Engineering Faculty. They would also like to thank Dr. Graham Walton, the Library's Service Development Manager for his support and helpful advice during the writing of this article. 


\section{Appendix 1}

\section{Have your say!}

Help us improve our service by answering as many of the questions below as you can.

\section{What we do}

Which of the following services offered by the Library's Engineering Faculty team have you either used or are aware of?

\section{Aware of Used}

Book ordering

Answering enquiries

Information literacy training

Study skills training

Interactive online training materials

One to one inductions

for new staff

Online newsletter for the

Engineering Faculty (Broadcast)

\section{Your Most Wanted...}

My top 3 most-wanted Library resources (journals, books, databases, etc) are:

1.

2.

3. 


\section{Help!}

I could do with some more training in....

l'd find it useful if I could access an Engineering Librarian via MSN (or similar). $\mathrm{Y} / \mathrm{N}$

\section{$4 \quad$ Institutional Repository}

Have you heard of the Institutional Repository? Y/N

I'd put my research papers on the Institutional Repository if...

\section{$5 \quad$ News and views}

What would be your preferred method of receiving news from the Library's Engineering Faculty team?

Via e-mail

From web pages

Via a Blog

Via an RSS feed

Other

\section{And you are...?}

Dept: AA, EL, CV, CG, MM

Staff type: Academic, Research, PhD, Management, Administrative 


\section{$7 \quad$ Anything else?}

Is there any other way the Library's Engineering Faculty team can support your teaching and research? Please use this space to give us any other comments.

\section{Thank you for your time!}

